\title{
Patterns of responding in a chained schedule altered by conditioned reinforcement'
}

\author{
DONALD W. ZIMMERMAN, Carleton \\ University, Ottawa 1, Canada
}

Rats responded on a two-component chained schedule. In the initial component responding on one lever produced an exteroceptive stimulus on a fixed-interval schedule; in the presence of the stimulus the first response on another lever produced primary reinforcement. Conditioned reinforcing properties of the stimulus were examined by presenting it on a variable. interval schedule in the first component, without primary reinforcement in the second component, while at the same time continuing the original fixed-interval schedule of primary reinforcement. The response pattern changed from one characteristic of a fixed-interval schedule to one characteristic of a variable-interval schedule. Control procedures indicated that the change could be attributed to conditioned reinforcing properties of the stimulus.

Responding on a chained schedule is attributed in part to primary reinforcement at the end of the chain and in part to conditioned reinforcement provided by the exteroceptive stimulus linking components of the chain (Ferster \& Skinner, 1957). There is considerable evidence that responding in the initial component of a chained schedule depends to some extent upon conditioned reinforcement and not solely upon terminal primary reinforcement (Kelleher \& Gollub, 1962). The present experiment, using a procedure related to one

A

$$
\begin{aligned}
R(\text { LEVER 1) } \overrightarrow{F I} & S \\
& R(L E V E R ~ 2) \underset{\text { CRF }}{\longrightarrow} \text { PRIMARY REINF }
\end{aligned}
$$

B
During six daily $1-\mathrm{h}$ sessions the chain was established. The first response on Lever 1 produced a stimulus consisting of a light and tone; then the first response on Lever 2 terminated the stimulus and produced access to $.1 \mathrm{cc}$ of water in a dipper feeder for 5 sec. Next, a 6 -min fixed-interval schedule (FI $6 \mathrm{~min}$ ) was established on Lever 1. The first response after $6 \mathrm{~min}$ produced the stimulus; the first response on Lever 2 terminated the stimulus and produced water.

Presentation of Stimulus on

Variable-Interval Schedule

Following 16 sessions under the FI 6-min schedule, additional presentations of the stimulus, not followed by water, were scheduled according to a variable interval. The schedule was an arithmetic series with a mean interval of $50 \mathrm{sec}$ (VI $50 \mathrm{sec}$ ). Responding on Lever 1 produced the stimulus after varying time periods; then the first response on Lever 2 terminated the stimulus but did not produce water. The original fixed-interval schedule also remained in effect. On the fixed-interval schedule responding on Lever 1 produced the stimulus after 6-min periods; on these occasions, the first response on Lever 2 terminated the stimulus and produced water. The procedure is shown schematically in Fig. 1. Conditions represented in Section A of the figure were in effect first; then the concurrent schedule represented in Section B was in effect. The schedule, either fixed-interval (FI) or continuous reinforcement (CRF), is indicated below the arrows. Presentation of Stimulus on

Variable-Interval Schedule without Association with Primary Reinforcement

After eight sessions under the above procedure, association of stimulus and primary reinforcement was omitted. The stimulus was presented after responses on Lever 1 according to the variable-interval schedule described above. On the fixedinterval schedule the first response on Lever 1 after 6 -min periods produced water; the second component of the chain was omitted. The stimulus was terminated $5 \mathrm{sec}$ after presentation if a response on Lever 2 did not occur. This procedure determined if reinforcing properties of the stimulus depended upon association with water.

Fig. 1. Schematic representation of experimental procedure. Line $A$ is chained schedule with fixed-interval and continuous reinforcement componen - Line B indicates concurrent 6-min fixt - -interval schedule of stimulus presentations with primary reinforcement in second component of chain and 50-sec variable-interval schedule of stimulus presentations without primary reinforcement in second component of chain. 


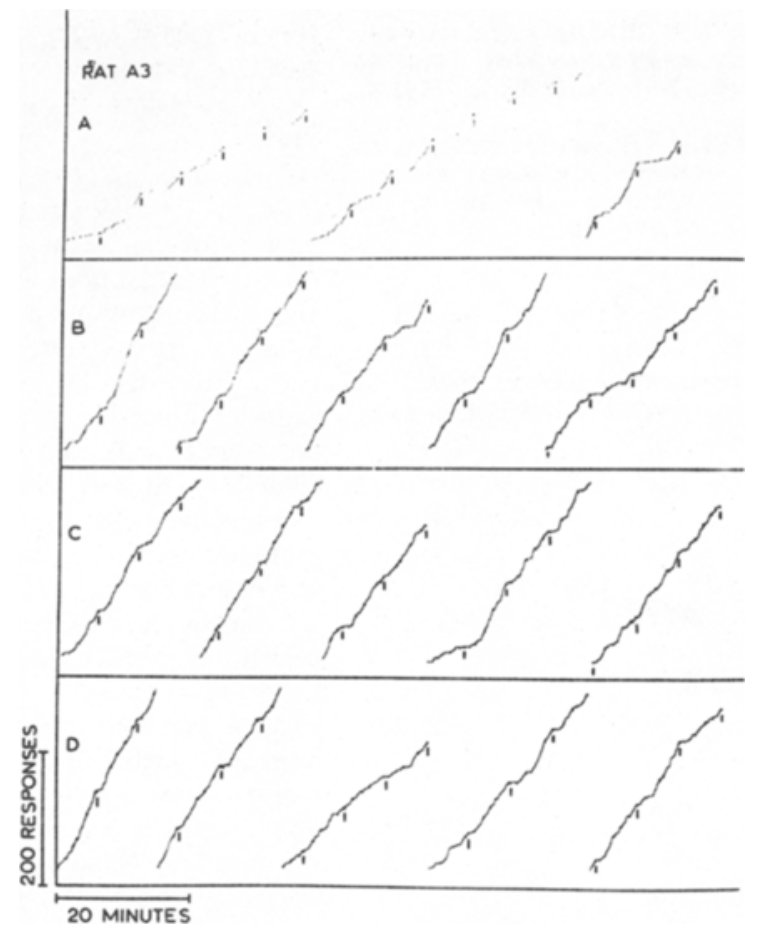

Presentation of Stimulus with No-Responding Criterion

Following eight sessions under the above procedure, the stimulus was presented after time interals which were the same as those of the variable-interval schedule described above, but at least $5 \mathrm{sec}$ after the last response on Lever 1 (differential reinforcement of other behavior, or DRO schedule). The first response on Lever 2 terminated the stimulus. Concurrently, after 6-min periods the first response on Lever 1 produced the stimulus; on these occasions the first response on Lever 2 produced water. This procedure determined if the stimulus could influence responding on Lever 1 even if it did not immediately follow a response on Lever 1 .

\section{RESULTS AND DISCUSSION}

The FI 6-min schedule on Lever 1 engendered positively accelerated responding. During the first session af ter change to the VI 50-sec schedule there was an increase in response rate and disruption of positively accelerated responding.Performance typical of a variable-interval schedule appeared and continued over eight sessions. Figure 2 shows a cumulative record of responding in the initial schedule component before and after the change in procedure. Record $A$ shows responding on Lever 1 during the last two sessions under the FI 6-min schedule.

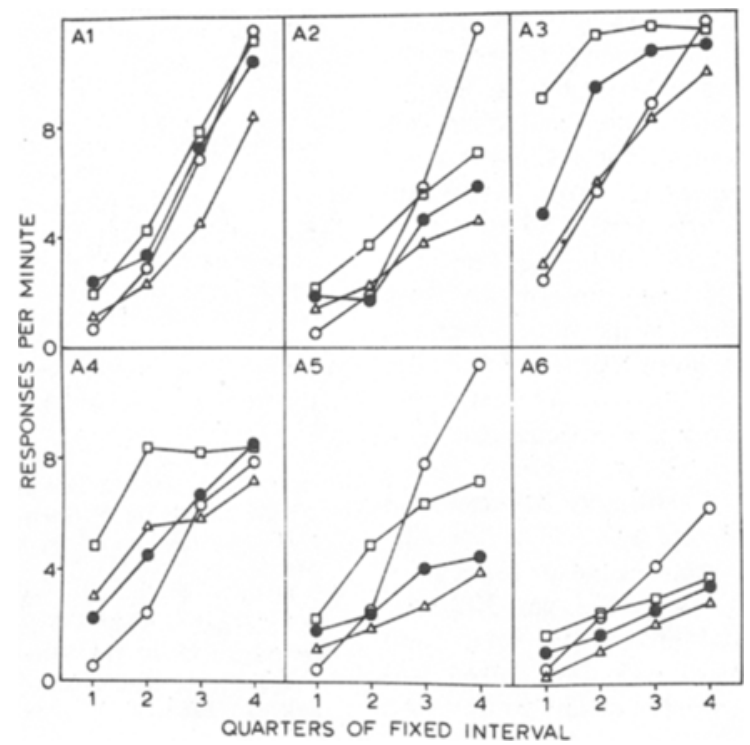

Fig. 2. Cumulative records of responding in initial component of chain (Rat A-3) under 6-min fixed-interval schedule (Record A) and under 50-sec variableinterval schedule of stimulus presentations concurrent with 6-min fixed-interval schedule (Records B, C, and D). Stimulus presentation is indicated by downward movement of recorder pen, and primary reinforcement is indicated by vertical marks below the record.

Beginning in Record $B$, and continuing in Records C and D, the VI 55-sec schedule of stimulus presentations was also in effect. Each of the four sections of the figure includes two daily sessions.

When association of stimulus and water was omitted, the response rate decreased. When the no-responding criterion was introduced, the rate became lower than on the original FI 6-min schedule. Performance of the six rats under all four procedures is summarized in Fig. 3, which plots mean response rates on Lever 1 in each quarter of the interval between presentations of the stimulus which were followed by primary reinforcement. Each point represents the mean rate of one rat over all in tervals during the last four sessions under each procedure.

In this experiment variation in the schedule of presentation of a stimulus linking two components of a chain altered the pattern of responding in the initial component, while the schedule on which primary reinforcement occurred at the end of the chain remained the same. Control procedures indicated that the change could not be attributed to effects of the stimulus which might occur even if it did not immediately follow a response and that its effectiveness was related to association with primary reinforcement. Since association of stimulus and primary reinforcement occurred regularly in the second component of the chain on the fixed-interval schedule, its capacity to act as a conditioned reinforcer in the first component on a variable-interval schedule was continuously maintained. The outcome was similar to that

Fig. 3. Mean response rate in initial component of chain in each quarter of interval of 6-min fixed-interval schedule of primary reinforcement. Performance under original 6-min fixed-interval schedule is indicated by open circles. Performance during sessions in which concurrent variableinterval schedule of stimulus presentations was in effect is indicated by squares. Performance during sessions in which association of stimulus and primaty reinforcement was omitted is indicated by solid circles. Performance during sessions in which stimulus was presented after variable time periods, at least $5 \mathrm{sec}$ after a lever response, is indicated by triangles. 
of a previous experiment (Zimmerman, 1969) which employed concurrent schedules of primary and conditioned reinforcement on a single lever. The present experiment provided evidence that respond. ing in the initial component of chained schedules depends upon conditioned reinforcing properties of the stimulus linking components of the chain.

REFERENCES

FERSTER, C. B., \& SKINNER, B. F. Schedules of reinforcement. New York: Appleton-CenturyCrofts, 1957
KELLEHER, R. T., \& GOLLUB, L. R. A review of positive conditioned reinforcement. Journal of the Experimental Analysis of Behavior, 1962,5, 543-597.

ZIMMERMAN, D. W. Concurrent schedules of primary and conditioned reinforcement in rats. Journal of the Experimental Analysis of Behavior, 1969, 12, 261-268.

\section{NOTE}

1. This research was supported by Grant APA-252-2057-13 from the National Research Council of Canada.

\section{Early cold stress and emotional reactivity in BALB/c mice: A brief note on Schaefer's temperature hypothesis}

\author{
RICHARD C. LaBARBA, ROYCE \\ HODGES, and JAN GERAGHTY, Univer- \\ sity of South Florida, Tampa, Fla. 33620
}

$B A L B / c$ mice subjected to temperatures of $10-12$ deg $C$ during the first week of life showed less emotional reactivity in an open field than did controls. It was found, however, that cold treatment of pups produces changes in maternal behavior which lead to an increase in the general stimulation level of the pups, and that this phenomenon may be confounding the data with regard to reductions in emotional reactivity.

In the course of studying the effects of early cold exposure on the response to pathogens in BALB/c mice, we had an unexpected opportunity to obtain some data on behavioral indices of emotional reactivity in a small number of mice as a function of early cold exposure. Schaefer $(1962,1963,1968)$ has presented cogent evidence that reduction in body temperature may be the basic variable in early handling phenomena. Mclver \& Camp (1966) found that Wistar rats exposed to temperatures of 3 or $7 \mathrm{deg} C$ during the first or second week of life were more active (less emotional) in an open field than were controls.

In the present study, two litters of $\mathrm{BALB} / \mathrm{c}$ mice were cold-treated by removing the mother from the litters and placing the cage in a refrigerator for $5 \mathrm{~min}$. The effect of this procedure was to reduce the internal cage temperature to approximately 10-12 deg C. The treatment was carried out for 4 days, from 2 to 5 days of age. A total of nine animals were used in the treatment group, the two litters consisting of four and five pups each. The control group of nine animals were subjected only to removal of the mother for $5 \mathrm{~min}$ a day over 2 to 5 days of age, with the cages left in the laboratory at room temperature $(72 \operatorname{deg} C)$. The control group also consisted of two litters of mice, one litter of four and one of five pups. Following treatment, all animals were weaned at 21 days of age and left undisturbed until 66 days of age. At this time, measures of activity level, quadrants traversed, and defecation were obtained during 3-min trials for 3 consecutive days in a Lehigh Valley automated open field. A mixed design analysis of variance was computed for each of the three dependent variables.

No significant differences on the measure of defecation were found between the experimental and control groups. On the measures of activity level and quadrants traversed, however, the cold-treatment group was significantly more active and mobile than controls $(\mathrm{F}=18.87, \mathrm{df}=1,16$, $p<.01 ; \quad F=20.64, \quad d f=1,16, \quad p<.01$, respectively). If one interprets these open-field measures in the typical manner, the experimental group was found to be less "emotional" than controls. That is, exposure to cold decreased emotional reactivity in these animals relative to controls. The mean number of quadrants traversed was 20.3 for controls and 33.6 for the experimental group. The means for activity level were 236.9 for controls and 309.3 for the experimental group. An interaction between treatment and days tested was found on the measure of quadrants traversed
$(\mathrm{F}=8.23, \mathrm{df}=2,32, \mathrm{p}<.01)$. Both activity measures showed a decrease from Day 1 to Day 3 of testing. No sex differences were found.

These data are generally consistent with those of McIver \& Camp (1966) insofar as they show a reduction of emotional reactivity in the open field as a function of early cold exposure, and seem to support Schaefer's temperature hypothesis. There may, however, be some confounding variables operating within cold-treatment procedures with rats and mice. In our laboratory, it was discovered that coldtreating the pups produced more or less profound reactions in the mother when she was returned to the litter. There occurs an intensification or distortion of maternal behavior patterns, characterized by a severe scattering of pups across the cage floor, frequent, random retrieval of pups, and a generally higher-than-usual amount of mother-infant interaction and stimulation. This pattern of high stimulation input for the pups may be contributing to reduction in emotional reactivity (Denenburg, 1964) since this maternal behavior pattern does not occur in the control groups. Therefore, it would appear that in early cold-stress studies there may be a resultant differential stimulation of the organisms involved, and perhaps confounding the results.

Mclver et al (1968) report findings of several other investigators in which changes in mother-pup interactions as a function of cold treatment are reported. It would appear that such observations are rather consistent, and that it now becomes necessary to carefully isolate changes in mother-infant relations from early temperature changes in assessing later behavioral changes in rats and mice.

\section{REFERENCES}

DENENBURG, V. H. Critical periods, stimulus input, and emotional reactivity: $A$ theory of infantile stimulation. Psychological Review, 1964, 71, 335-351.

McIVER, A. H., \& CAMP, B. Early cold stress: I. Effects on emotional reactivity in rats. Paper presented at the meeting of the American Psychological Association, New York, 1966.

MCIVER, A. H., JEFFREY, W. E., STEVENSON, M., \& NIELSON, H. C. Infantile handling and body temperature change in the rat: III. Early temperature change and its implications for later responses. Transactions of the New York Academy of Sciences, 1968, 30,992-1000.

SCHAEFER, T., \& TOWNE, J. C. Temperature change: The basic variable in the early handling phenomenon? Science, 1962, 135, 41-42.

SCHAEFER, T. Early "experience" and its effects on later behavioral processes in rats: 11. A critical factor in the early handling phenomenon. Transactions of the New York Academy of Sciences, 1963, 25, 871-889.

SCHAEFER, T. Infantile handling and body temperature change in the rat: 1 . Initial investigations of the temperature hypothesis. Transactions of the New York Academy of Sciences, 1968, 30, 977-984. 